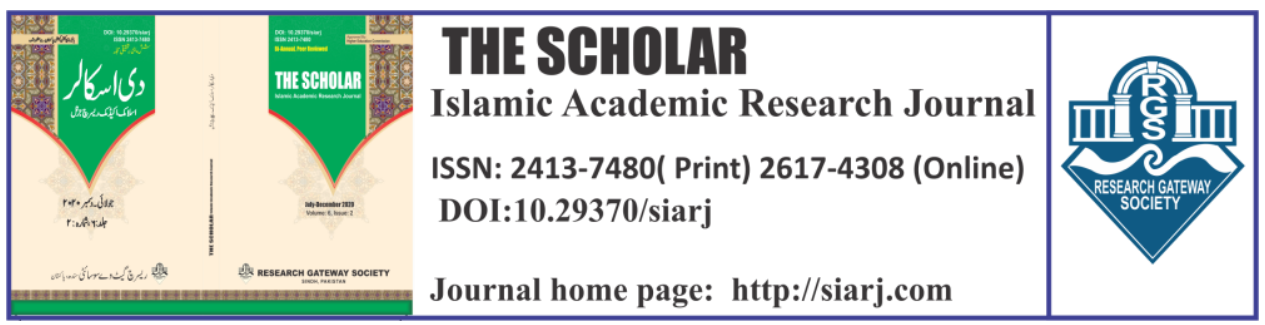

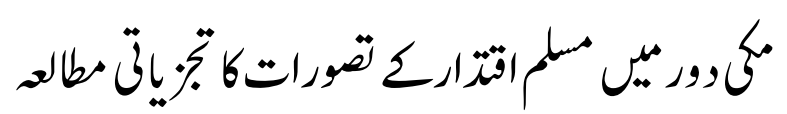

\title{
ANALYTICAL STUDY OF THE CONCEPTS OF MUSLIM POWER IN THE MAKKĪ ERA
}

\section{Muhammad Ajmal Khan}

PhD Scholar, Department of Islamic and

Religious Studies, Hazara University Mansehra

Email: ajmal13101@gmail.com

\section{ORCID ID:}

\section{https://orcid.org/0000-0002-7274-2412}

\section{Syed Azkia Hashimi}

Chairman department of Islamic and Religious Studies Hazara University, Mansehra

Email:_azkiahashimi@gmail.com

\section{ORCID ID:}

https://orcid.org/0000-0003-3722-3518

To cite this article:

Khan, Muhammad Ajmal, and Syed Azkia Hashimi. "URDU-ANALYTICAL STUDY OF THE CONCEPTS OF MUSLIM POWER IN THE MAKKĪ ERA." The Scholar-Islamic Academic Research Journal 6, No. 2 (December 31, 2020): 43-54.

To link to this article: https://doi.org/10.29370/siarj/issue11urduar3

Journal

Publisher

DOI:

URL:

License:

Journal homepage

Published online:
The Scholar Islamic Academic Research Journal

Vol. 6, No. 2 || July-December 2020 || P. 43-54

Research Gateway Society

10.29370/siarj/issue11urduar3

https://doi.org/10.29370/siarj/issue11urduar3

Copyright c 2017 NC-SA 4.0

www.siarj.com

2020-12-31
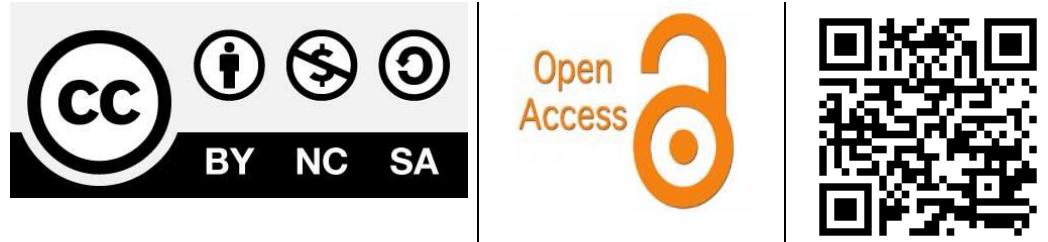


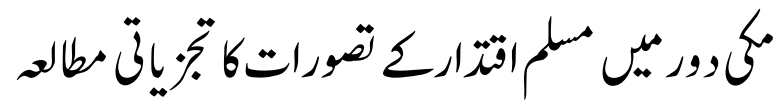 \\ ANALYTICAL STUDY OF THE CONCEPTS OF MUSLIM POWER IN THE MAKKĪ ERA
}

\author{
Muhammad Ajmal Khan, Syed Azkiah Ashimi
}

\begin{abstract}
:
Details of Madani era are available in the chronicles of history \& Sirah, but this aspect is somewhat terse research, as to when do the efforts to establish the states of Madinah begin? Obviously, the establishment of the state of Madinah is not a coincidence but it was already been planned for, efforts have been made for its establishment and It must have been a reaction too. Therefore, in the Mecca era when did the Holy Prophet think of establishing a state? On what occasions did he express it? Did his opponents understand his thinking? Who they were and how they reacted? What was the ruling of Allah to him in this regard? This article enlights all the above-mentioned aspects and concludes that the establishment of the state of Madinah is not an accident, but the result of Prophet's constant struggle in the Mecca period, which he has expressed on various occasions. Arab leaders, as well as Jews of Madinah, knew about the prophet's views for the establishment of a state in the near future and opposed him either by creating obstacles in the preaching of Islam or by removing the shreds of evidence from the previous religious literature such as Bible.
\end{abstract}

KEYWORDS: Sirah, Madina, Islamic State, Makkī Era

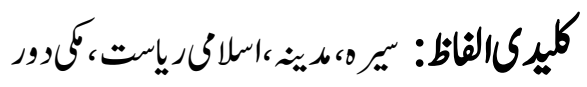
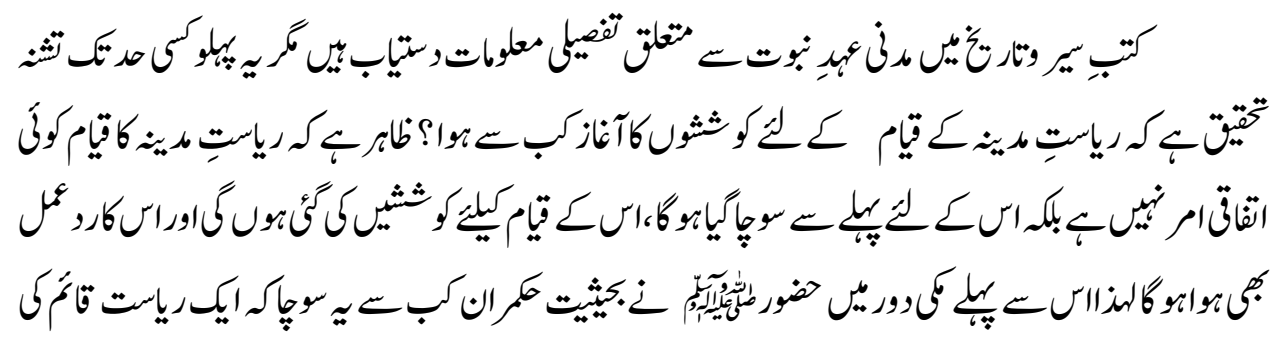


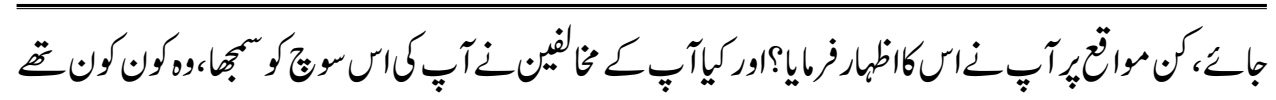

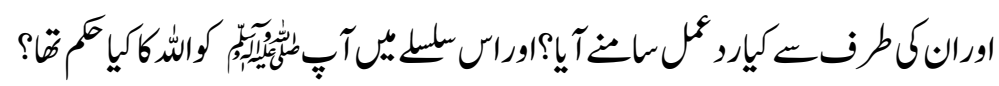

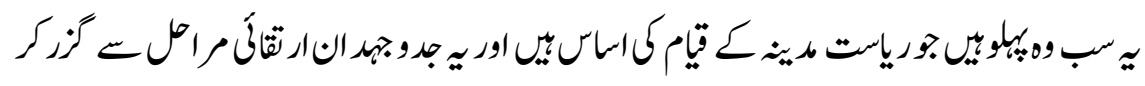

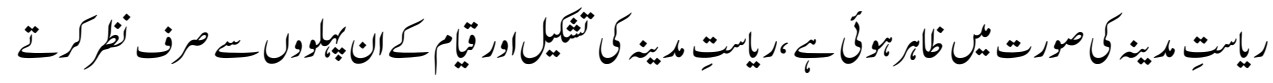

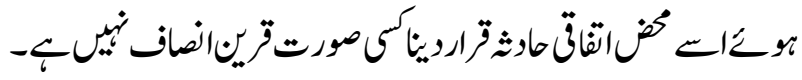

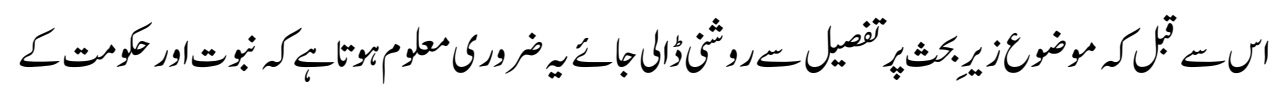

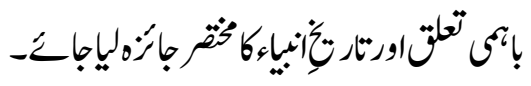

\section{نى.كيثيتيث كمران:}

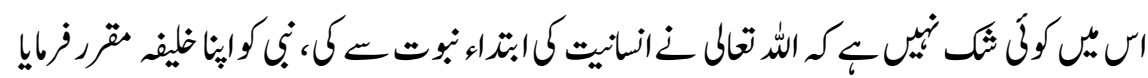

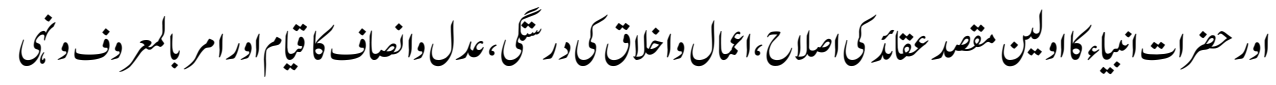

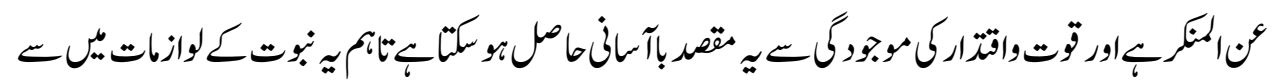

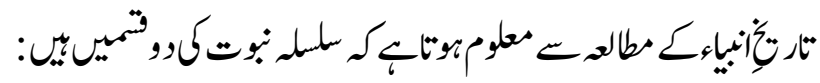

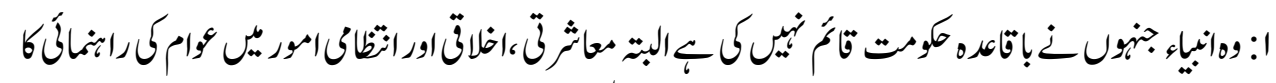

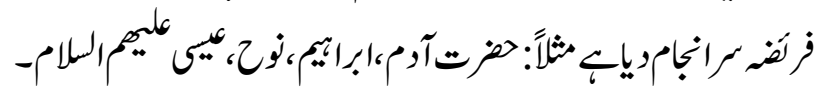

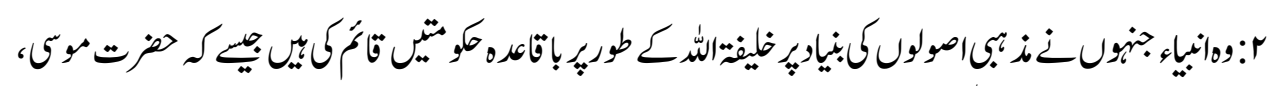

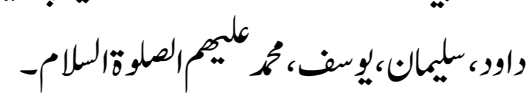

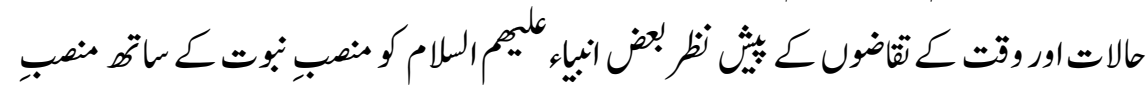

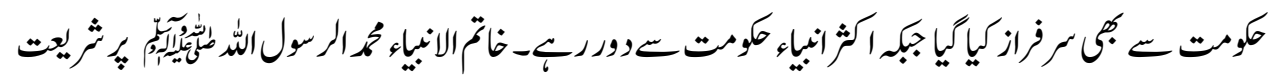

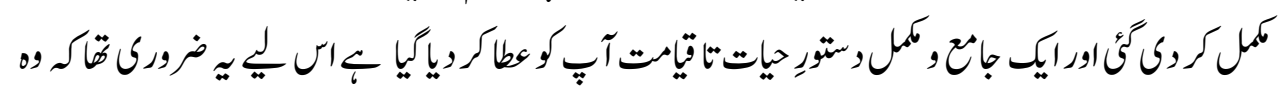

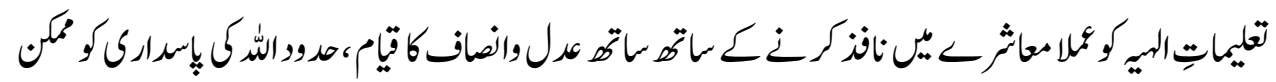




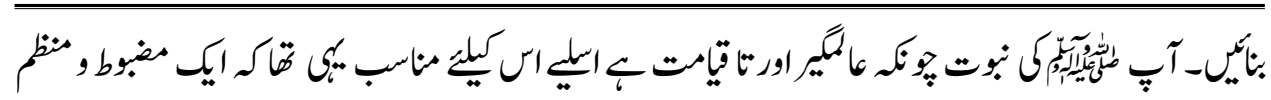

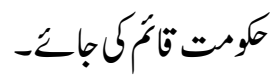

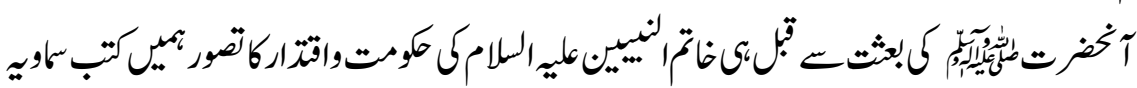

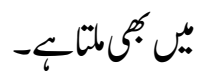

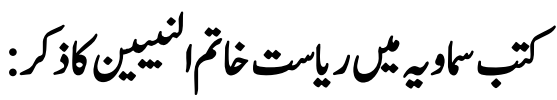

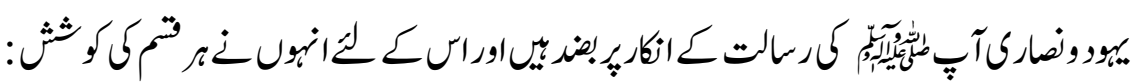

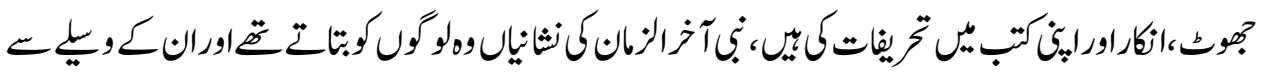

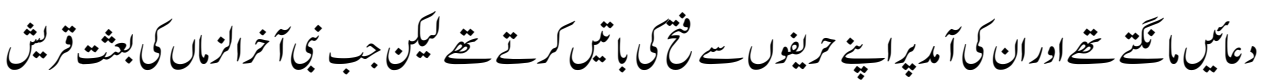

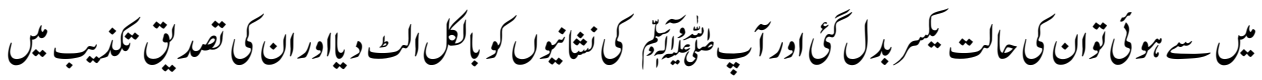

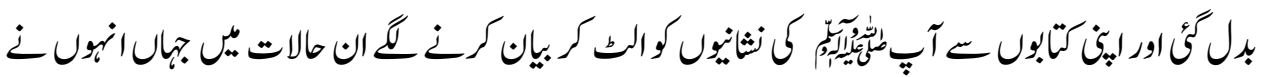

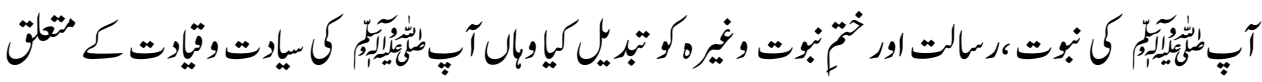

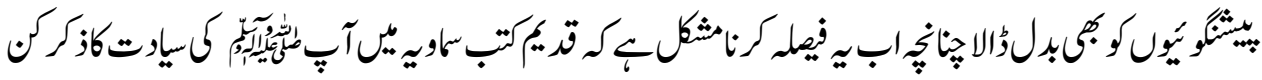
الفاط كساتهواب؟

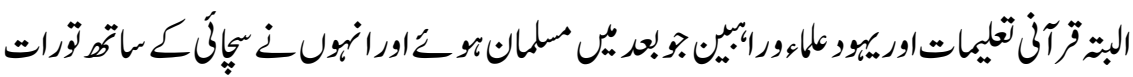

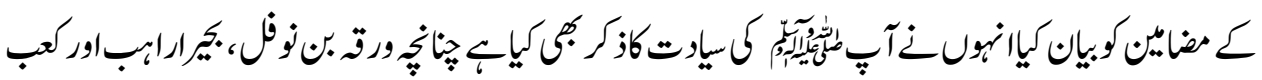

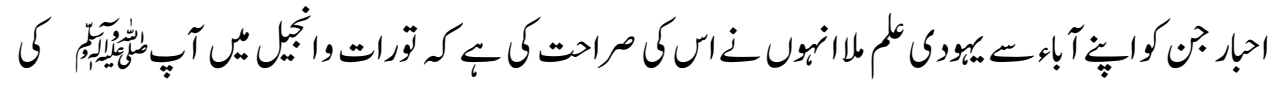

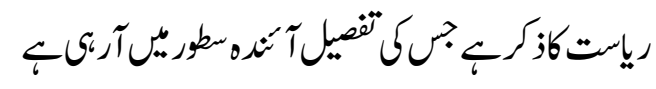

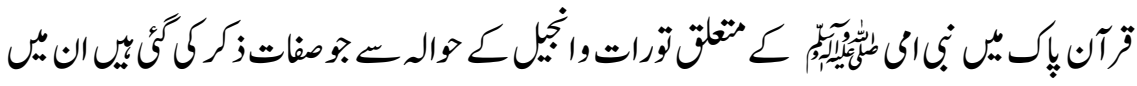

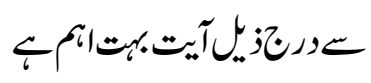
النين يتبعون الرسول النبى الامى النىى يجلاونه مكتوباعندهم فى 


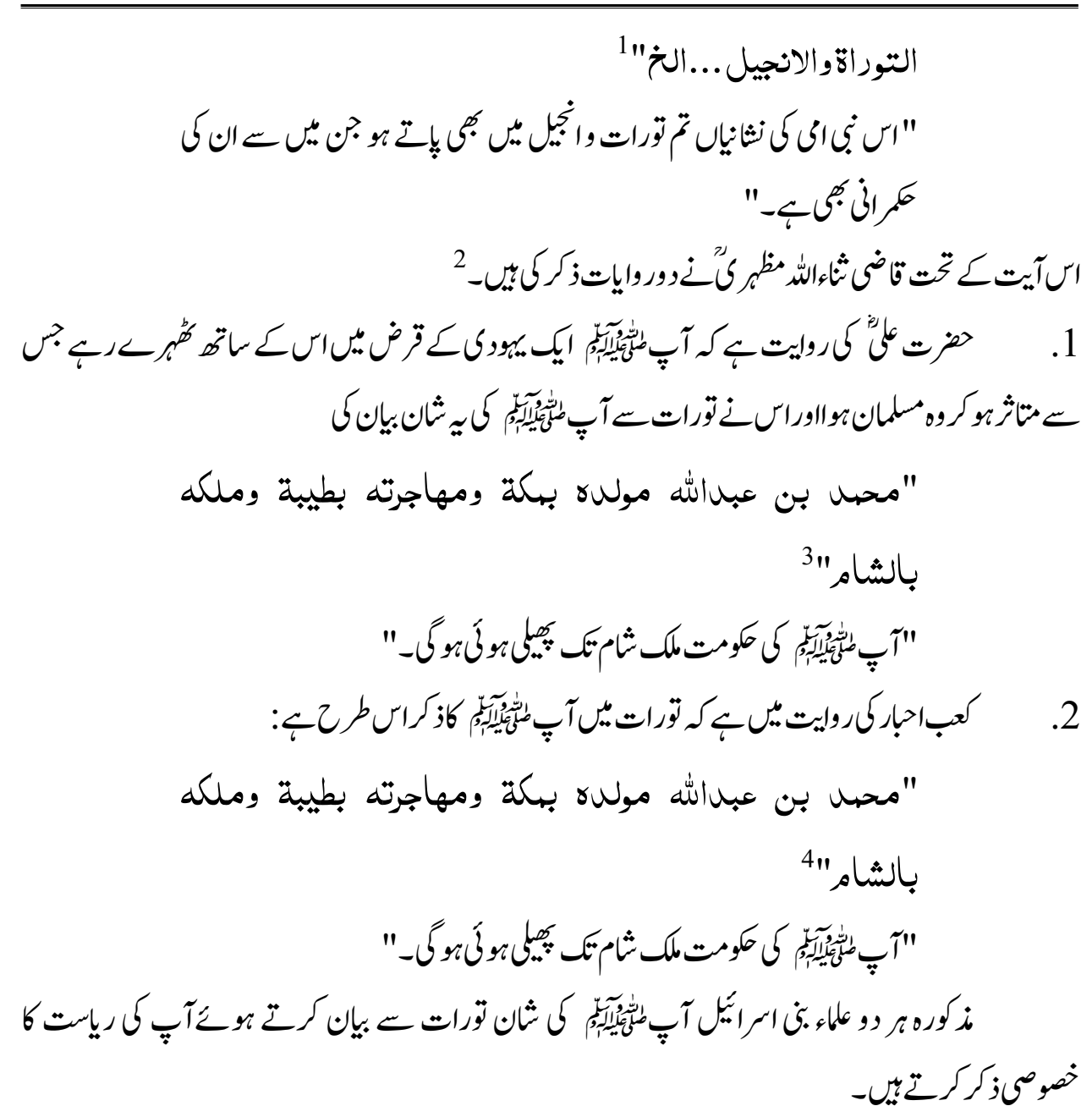

${ }^{1}$ Sūrah al 'A'rāf, 157

${ }^{2}$ Maẓharī, Muḥammad Sanā Ullah, Al Tafsīr al Maẓharī, (Pakistan: Maktabah al Rashīd), 3: 417

${ }^{3}$ Al Bayhaqī, Abū Bakr Aḥmad bin Husayn, Dalā'il al Nabūwah wa Ma'rifah Aḥwāl Ṣāhib al Sharī'ah, (Beirut: Dār al Kutub al 'Ilmiyyah, ), 6: 281

${ }^{4}$ Al Dārmī, 'Abdullah bun 'Abd al Raḥmān, Aḥmad, Musnad al Dārmī, (KSA: D ā r al Mughn ī lil Nashr wal Tawz î̀), 1: 156 


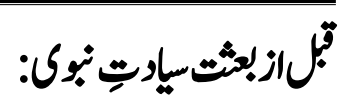

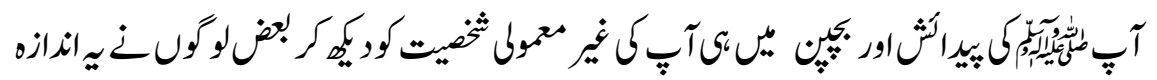

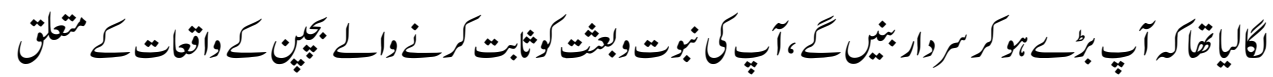

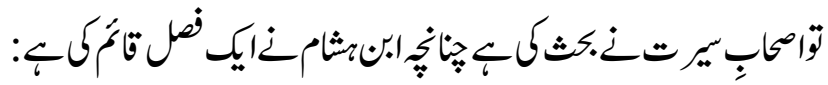

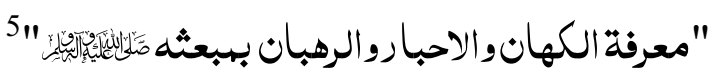

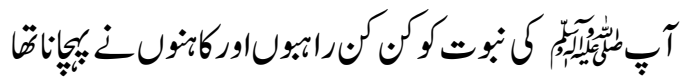

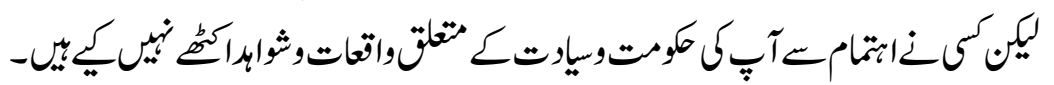

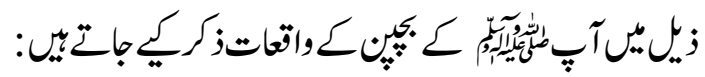

1.

انكتقحملت بسيلهن الامة

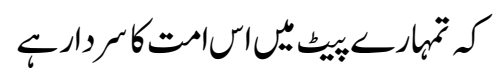

2.

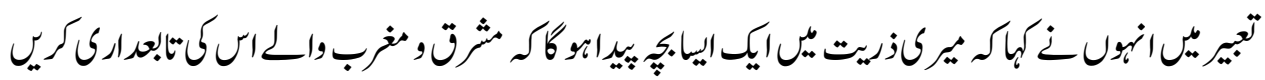

3.

كاباته كيمرك كما:

هنا سيل العالين هنا رسول رب العالهين يبثه الهه رحة للعالهين 8

5 Ibn Hishām, 'Abd al Malik bin Hishām, Al Sīrah al Nabawiyyah, (Maktabah al Saqā), 1: 204

${ }^{6}$ Muḥammad bin Ishāa bin Yasār, Sīrah ibn Isḥāq, (Beirut: Dār al Fikr), 1: 45

${ }^{7}$ Al Suhaylī, 'Abd al Rạ̣mān bin 'Abdullah, Al Raw ḍ al Anaf, (Beirut: Dār Iḥyā' al Turath al 'Arabī), 2: 95

${ }^{8}$ Ibn Kathīr, Ismā'īl bin 'Umar, Al Sìrah al Nabawiyyah, (Beirut: Dār al Ma'rifah lil Ṭabā'ah wal Nashr), 1: 246 


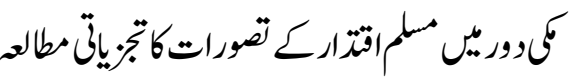

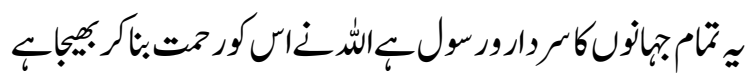

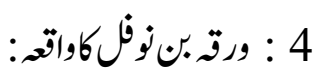

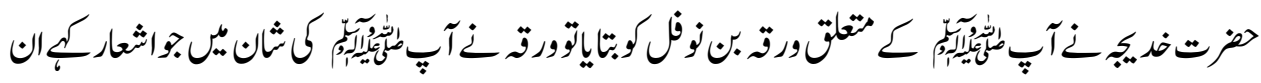

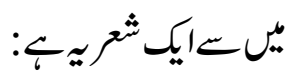

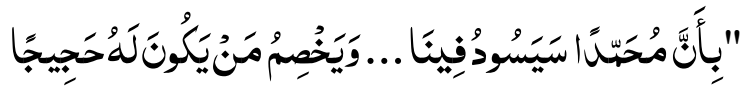

9

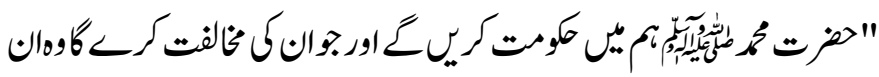

"

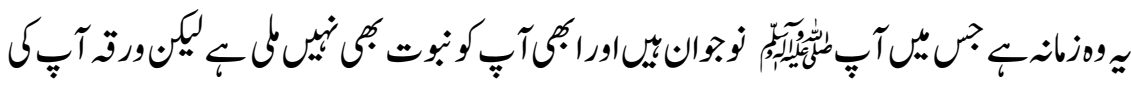

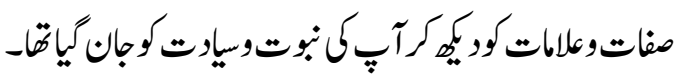

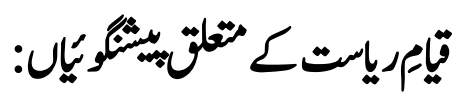

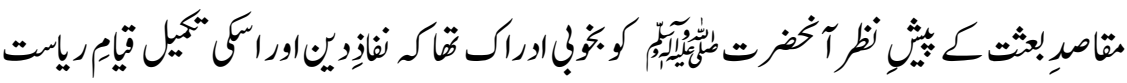

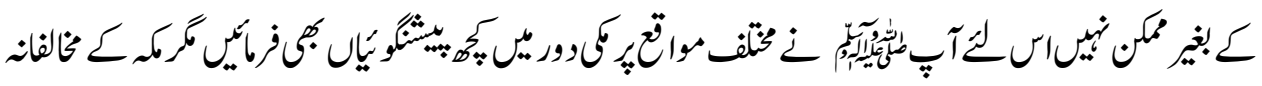

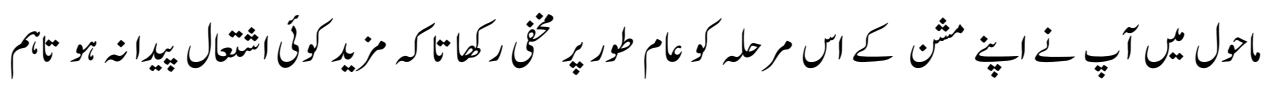

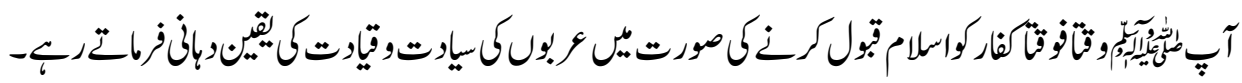

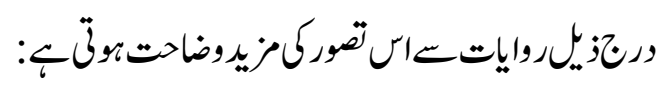

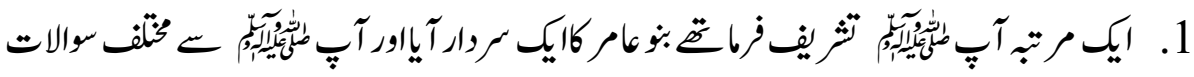

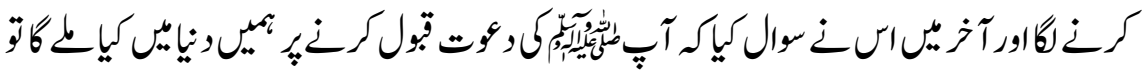

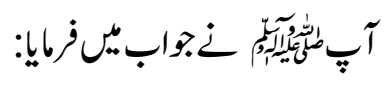

"النصصوالتبكنف البلاد" 10

${ }^{9}$ Ibn Hishām, Al Sīrah al Nabawiyyah, 1: 176 


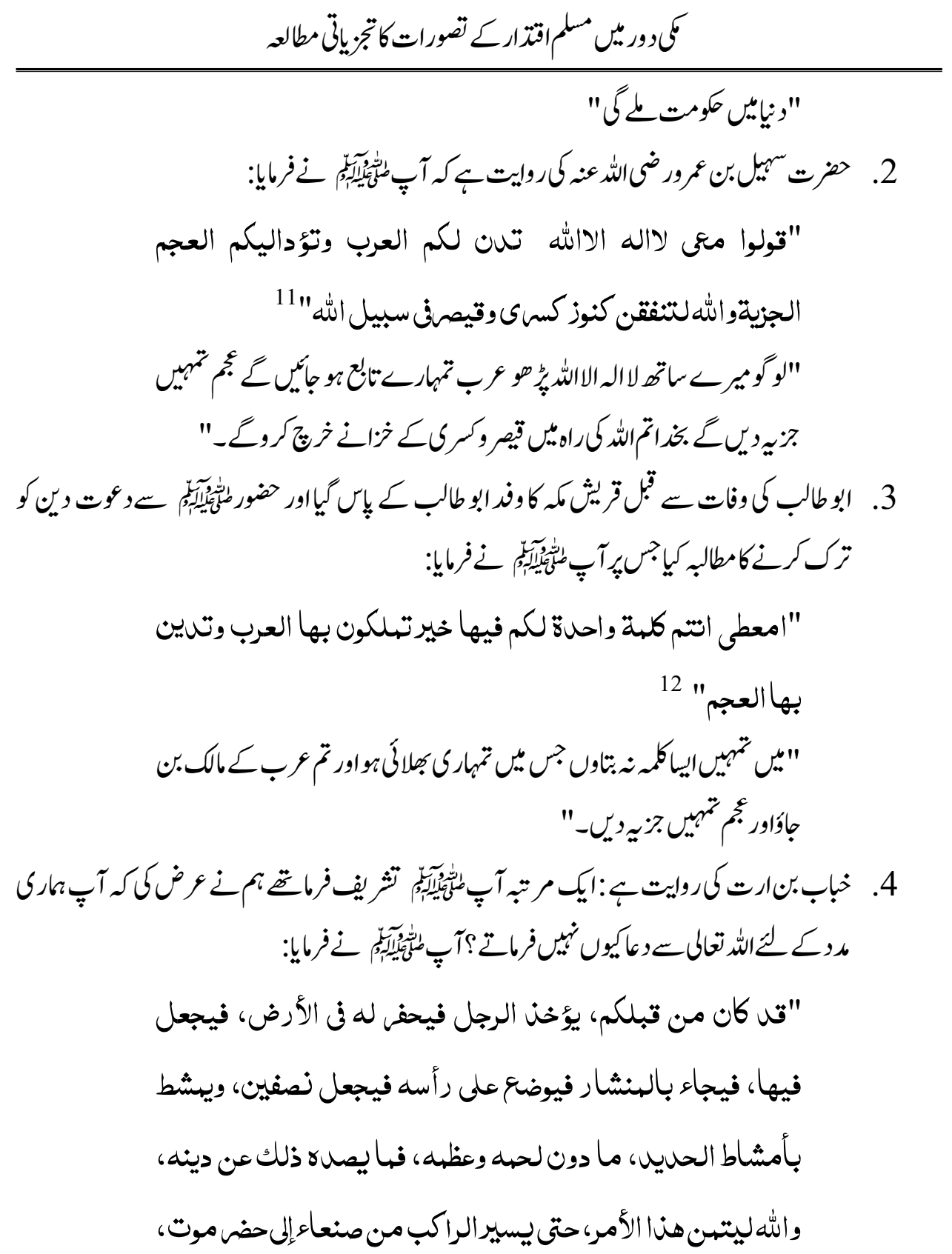

${ }^{10}$ Ibn al Athīr, 'Alī bin Abī al Karam, Al Kāmil fì al Tārīkh, (Beirut: Dār al Kitāb al 'Arabī), 1: 423

${ }^{11}$ Ibn al Athīr, Al Kāmil fì al Tārīkh, 1: 186

${ }^{12}$ Muḥammad bin Isḥāq, Sīrah ibn Ishạq , 1: 236 


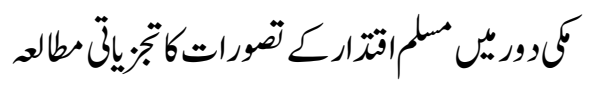

$13 "$

لايخاف إلا الله، والنئب على غنهه، وركنكم تستعجلون

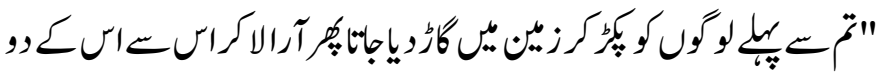

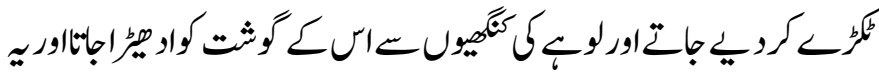

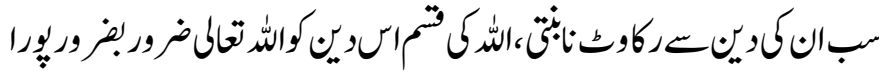

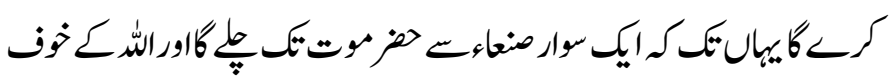

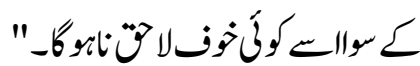

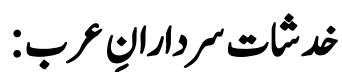

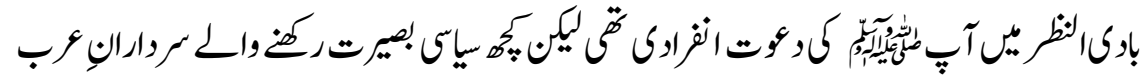

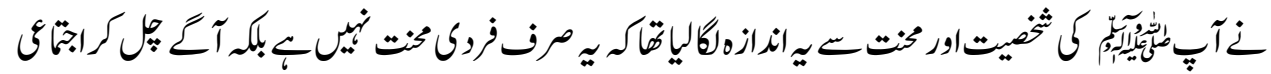

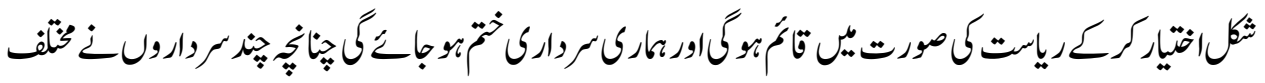

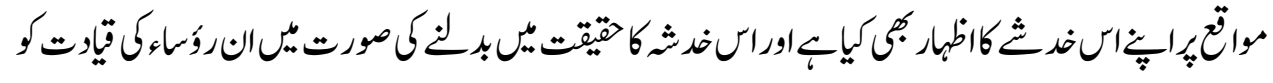

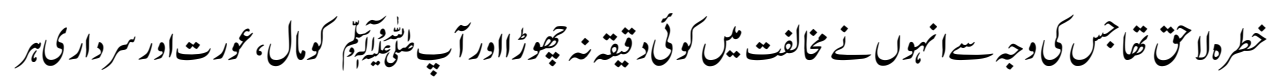

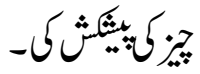

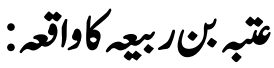

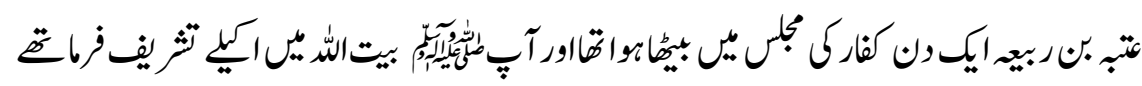

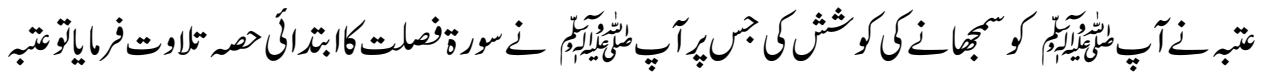

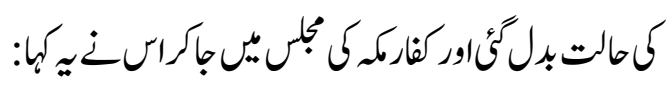

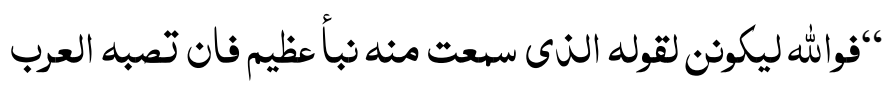

فقل كفيتهول بغيركم وان يظهرعلى العرب فهلكه ملككم وعزلهزكم

${ }^{13}$ Al Bukhārī, Muḥammad bin Ismā‘n̄l, Șaḥ̄ḥ Al Bukhārī, (Dār Ṭawq al Naj āh), Hadīth \# 6943 


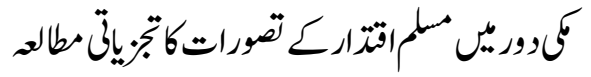

$$
\begin{aligned}
& \text { وكنتم اسعص الناس بلسانه" } 14
\end{aligned}
$$

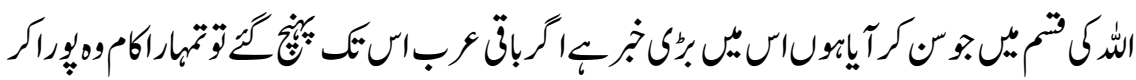

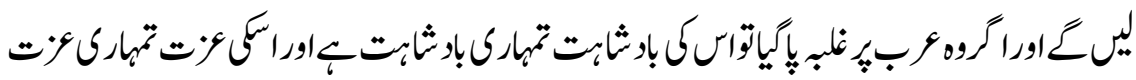

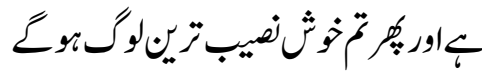

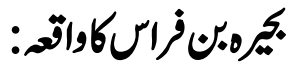

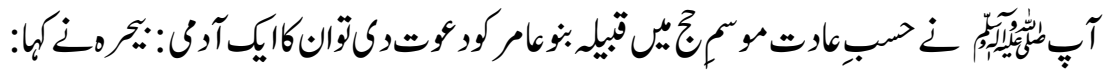

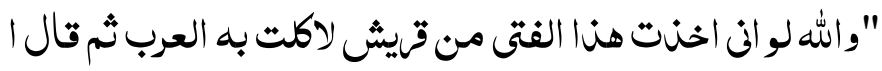

$$
\begin{aligned}
& \text { رايت ان نحن تابعناك على امرك ثم اظهرك الله على من خالفك } \\
& \text { ايكون لنا الامر من بعدك مـ قال الامر الى الله يضعه حيث } \\
& \text { يشاء"15 }
\end{aligned}
$$

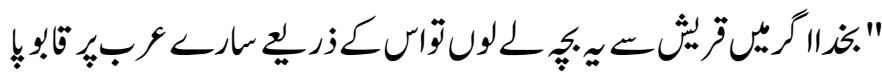

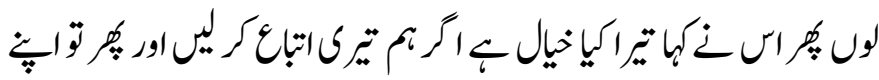

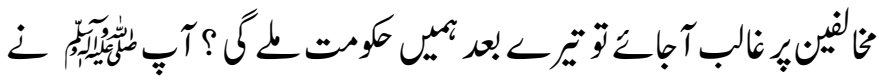

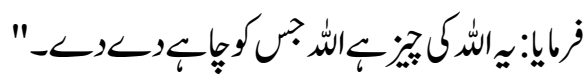

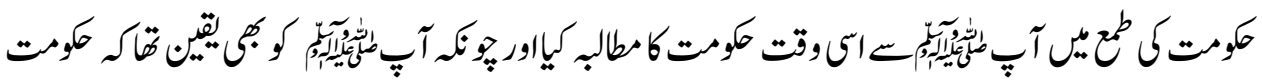

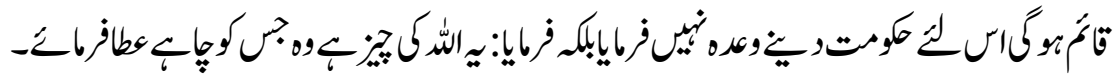

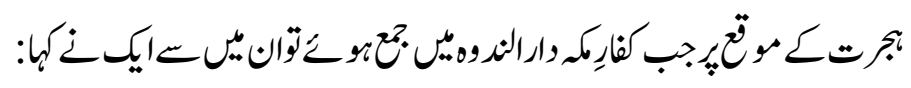

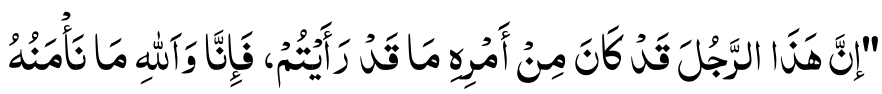

${ }^{14}$ Ibn Hishām, Al Sìrah al Nabawiyyah, 1: 262

${ }^{15}$ Ibn Hishām, Al Sīrah al Nabawiyyah, 2: 51 


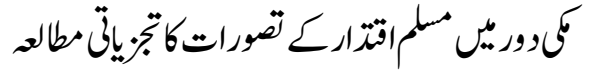

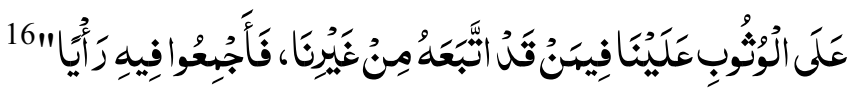

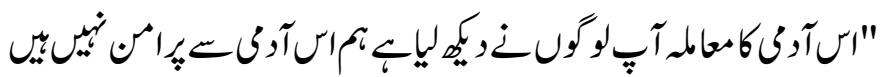

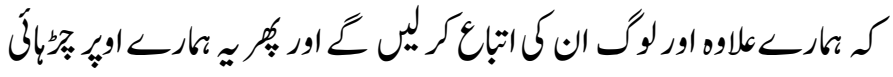

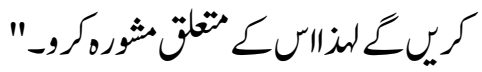

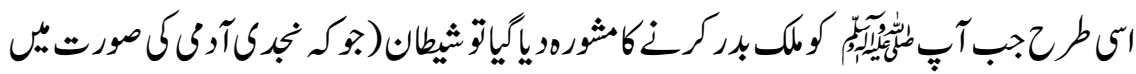

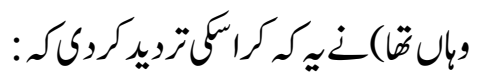

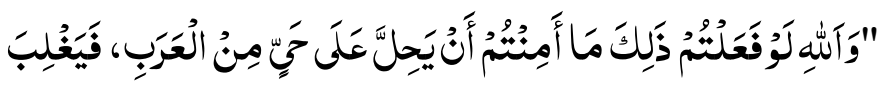

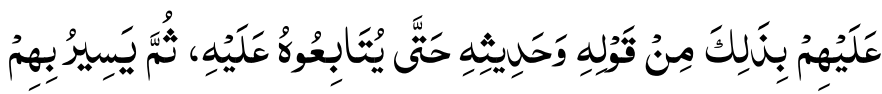

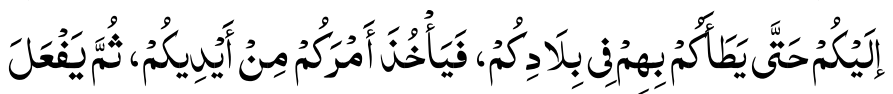

$$
\begin{aligned}
& \text { بِكَمْ مَاََْرادَ" } 17
\end{aligned}
$$

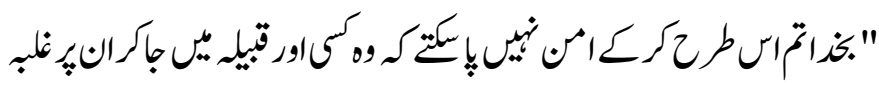

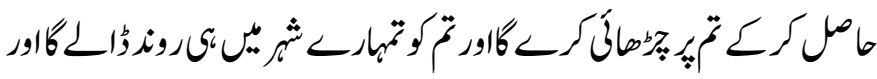

$$
\begin{aligned}
& \text { 苗 }
\end{aligned}
$$

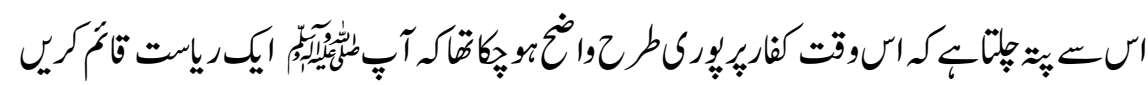

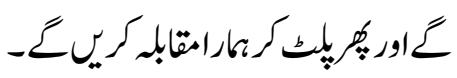

$$
\begin{aligned}
& \text { تمأُمث: } \\
& \text { 1. }
\end{aligned}
$$

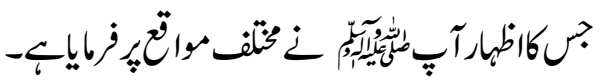

${ }^{16}$ Ibn Hishām, Al Sīrah al Nabawiyyah, 2: 481

${ }^{17}$ Ibn Hishām, Al Sìrah al Nabawiyyah, 2: 482 
The Scholar Islamic Academic Research Journal

Vol. 6, No. 2 || July-December 2020 || P. 43-54

https://doi.org/10.29370/siarj/issue11urduar3

2.

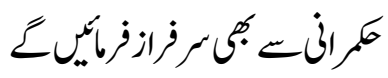

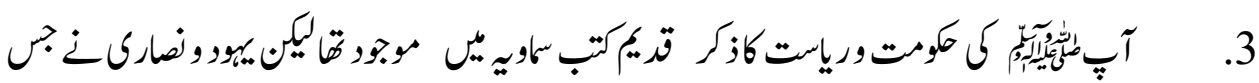

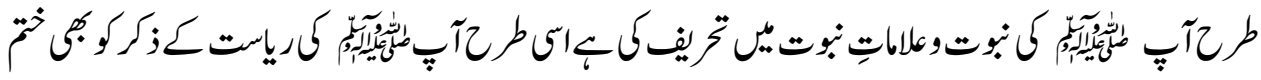
كروالا

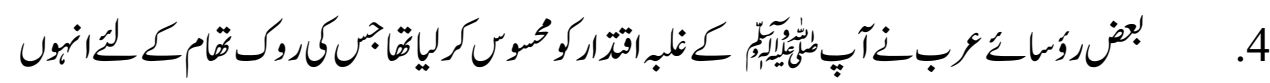

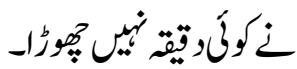
5

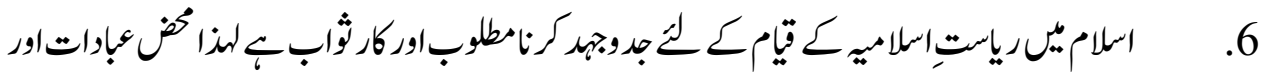

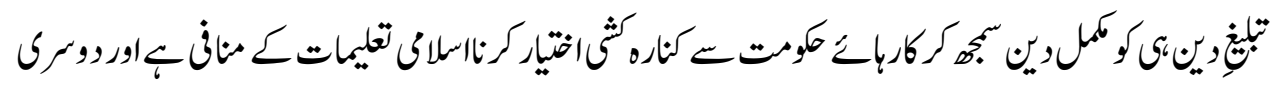

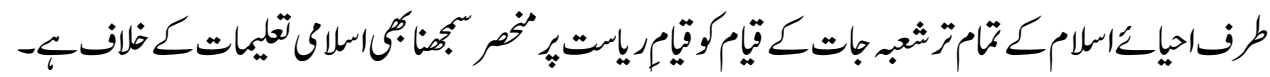

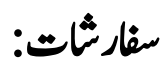

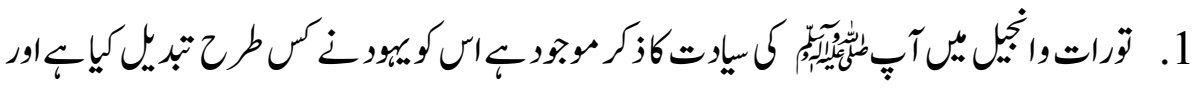

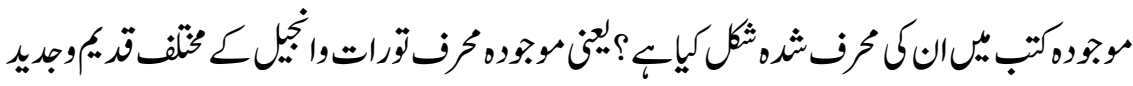
تخون 
The Scholar Islamic Academic Research Journal

Vol. 6, No. 2 || July-December 2020 || P. 43-54

https://doi.org/10.29370/siarj/issue11urduar3

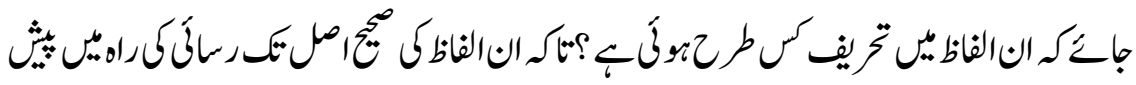

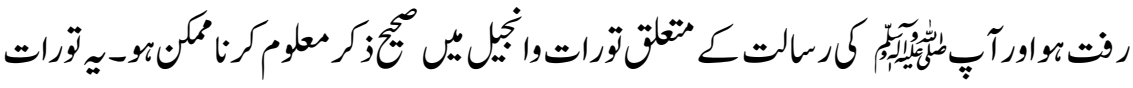

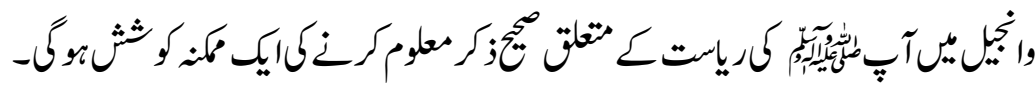

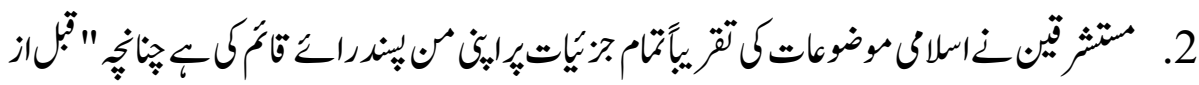

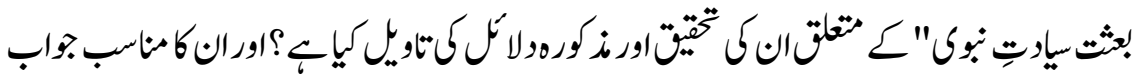

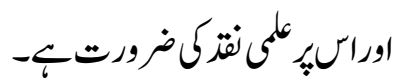

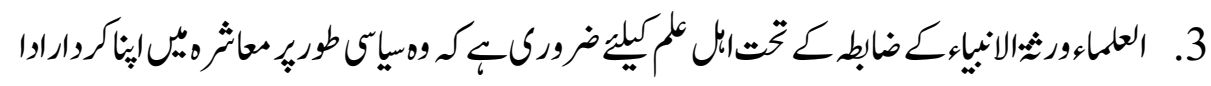

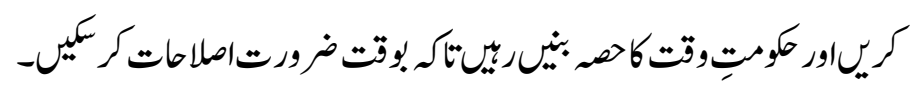

\section{(c) (P) (O)}

Attribution-NonCommercial-ShareAlike 4.0 International (CC BY-NC-SA 4.0) 